\title{
CORONA imagery in the analysis of the forest- tundra ecotone in Kuznetsk Alatau (Orligtaskhyl Mountain)
}

\author{
Sergei $\operatorname{Im}^{1,2,3^{*}}$, Il'ya Petrov ${ }^{1}$, and Viacheslav Kharuk $^{1,2}$ \\ ${ }^{1}$ V.N. Sukachev Institute of Forest SB RAS (FRC KSC SB RAS), 660036 Krasnoyarsk, Russia \\ ${ }^{2}$ Siberian Federal University, 660041 Krasnoyarsk, Russia \\ ${ }^{3}$ M.F. Reshetnev Siberian State University of Science and Technology, 660037 Krasnoyarsk, Russia
}

\begin{abstract}
Changes in the forest-tundra ecotone of Orligtashyl mountain (Kuznetsk Alatau) were analyzed based on the available satellite CORONA (1971) and Wordlview (2013) imagery. Forest stands were identified on the Worldview scene using Iso cluster classification. On the CORONA scene stands were differentiated from the background area using statistical analysis of histogram of the identified classes' brightness values and were harmonized with the classification of the Wordlview imagery. Kappastatistics showed good accuracy $(\kappa=0.93)$ of the Wordlview imagery classification and the average for CORONA $(\kappa=0.67)$. Area of stands increased by $\sim 38 \%$ during the analyzed period. Maximal area increase was observed on the south-eastern warm slopes. Significant changes were determined on the elevational boundary of the ecotone where the stands' elevation boundary shifted up by $\sim 9 \mathrm{~m}(0.2 \mathrm{~m} / \mathrm{yr}$.). GIS analysis revealed that trees form elongated clusters mainly directed across the slope. Observed changes occurred along with summer temperature increase during 19712013 by $0.3^{\circ} \mathrm{C} /$ decade $\left(\mathrm{r}^{2}=0.32, \mathrm{p}<0.01\right)$.
\end{abstract}

\section{Introduction}

An acceleration of trees' growth and trees' expansion by elevation gradient are observed since the end of the 20th century [1]. Such changes can be estimated based on the mediumresolution remote sensing data and GIS. Very high-resolution remote sensing data can improve the accuracy of assessment of the vegetation cover dynamics in the forest-tundra ecotones, these allow to account for individual trees [2]. In this paper, vegetation cover dynamics within the mountainous forest-tundra ecotone of Kuznetsk Alatau was investigated based on the CORONA and Worldview very high-resolution remote sensing data.

\footnotetext{
* Corresponding author: stim@ksc.krasn.ru
} 


\section{Materials and methods}

\subsection{Study area}

The mountainous forest-tundra ecotone in Kuznetsk Alatau (Orligtaskhyl Mountain; $54^{\circ} 06^{\prime} 23^{\prime \prime} \mathrm{N} ; 89^{\circ} 04^{\prime} 08^{\prime \prime} \mathrm{E}$; fig. 1) was investigated. The height of the mountain is $1454 \mathrm{~m}$. The administrative border between Khakassia and Kemerovskaya oblast crosses the mountain. The study area is 451 ha. In this region Siberian pine (Pinus sibirica) is the dominant tree species. The total amount of the annual precipitation is $560 \pm 61 \mathrm{~mm}$, winter $-68 \pm 17 \mathrm{~mm}$, and summer - $235 \pm 40 \mathrm{~mm}$. Mean annual temperature is $-3.0 \pm 1.0^{\circ} \mathrm{C}$, winter $-21.0 \pm 2.6^{\circ} \mathrm{C}$, and summer $-+13.7 \pm 0.8^{\circ} \mathrm{C}$.

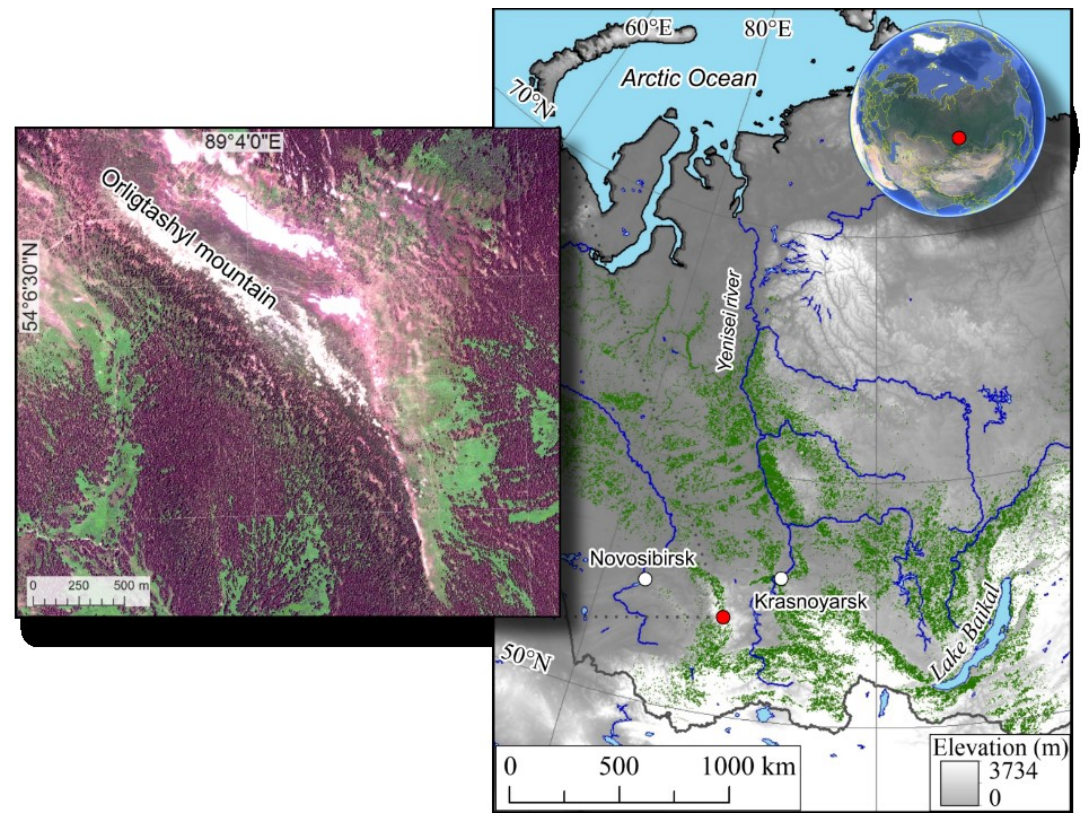

Fig. 1. Study site location (red circle) - the forest-tundra ecotone in Kuznetsk Alatau (Orligtaskhyl Mountain; $\left.54^{\circ} 06^{\prime} 23^{\prime \prime} \mathrm{N} ; 89^{\circ} 04^{\prime} 08^{\prime \prime} \mathrm{E}\right)$. The inserted box - Worldview-2 scene (14.07.2013) of the study area. Green on the sketch-map indicates birch stands.

\subsection{Data used}

\subsubsection{Remote sensing data}

We assessed spatio-temporal variations of the forest-tundra ecotone based on the remote sensing data received by the Corona J-3 (KH-4B satellite included to reconnaissance CORONA program (USA); scene obtained in 16.09.1971; the spatial resolution is $1.8 \mathrm{~m}$ ) [3], and Worldview-2 (14.07.2013 г.; the spatial resolution is $0.5 \mathrm{~m}$ ) satellites. Corona scene was acquired using USGS Earth Explorer internet geoportal (https://earthexplorer.usgs.gov). Worldview-2 scene was obtained from Bing Maps online service using SAS Planet software (http://www.sasgis.org/sasplaneta). We used digital elevation model SRTM GL1 (https://lpdaac.usgs.gov/ products/srtmgl1v003; $30 \mathrm{~m}$ spatial resolution) to analyze relations of vegetation dynamics with topography. 


\subsubsection{Ground data}

Ground data were collected during the fieldwork realized in the 2016 year. In total 12 test plots were established. GPS coordinates, forest inventory, landscape, and soil data were recorded.

\subsubsection{Climate data}

We used climate data extracted from the CRU TS 4.05 dataset for 1971-2013 years (https://crudata.uea.ac.uk/cru/data/hrg/cru_ts_4.05). The spatial resolution is 0.5 degrees. Temperature and precipitation data were analyzed only.

\subsection{Spatial analysis}

A classification map based on the 2013-year Worldview scene was created using Iso cluster unsupervised algorithm [4]. Based on ground data and visual expert analysis initially created 50 classes were merged into the two final classes: (1) darkneedle stands (height $>3 \mathrm{~m}$, closure $>0.2$ ); (2) background (fig. 2). KHAT(к)-statistics [4] was used to estimate classification accuracies based on 458 uniformly spatially distributed test points. These test points were identified based on on-ground data and expert analysis of the scene. The total classification accuracy is $95 \%(\kappa=0.93)$.

The 1971-year CORONA scene was georeferenced to the 2013-year Worldview scene using splines because of considerable nonlinear geometric distortions. In total, 1107 tie points were used. Typical polygons of darkneedle stands (with height $>3 \mathrm{~m}$ ) were selected on the grayscale CORONA scene. These polygons were used to estimate statistical variations of brightness of darkneedle stands. Computed statistical data were used to identify darkneedle stands on the CORONA scene. Pixels' brightness of darkneedle stands was in the range of 8-72. Further, the 1971-year classification map was improved by harmonization it with the 2013 -year classification map. Total accuracy of the 1971-year classification map is $87 \%$ $(\kappa=0.67)$ (fig. 2).

GIS-analysis analysis was realized using ESRI ArcGIS Desktop. Microsoft Excel was used to make statistical computations.

\section{Results and discussion}

During the observed period (1971-2013, 42 years) area of darkneedle stands increased by $38 \%(0.9 \%$ per year; fig. 2). Trees' area increase was not uniform in respect to topography. Most changes were identified on the top of the mountain (1300-1400 m a.s.l.) in the foresttundra ecotone where the area of the detected trees increased by $\sim 150 \%$. Elevation trees' boundary (100-highest pixels) shifted up by $\sim 9 \mathrm{~m}(0.2 \mathrm{~m}$ per year). It coincides with ground measurements $(0.2-0.3 \mathrm{~m}$ per year) [5]. This value is slightly lower than the median one for the northern hemisphere ( $0.35 \mathrm{~m}$ per year) [1]. The maximum of trees' area increase was on the southern and south-western slopes. On the north-eastern macro-slope of the mountain, trees growth $\sim 100 \mathrm{~m}$ lower than ones on the south-western macro-slope. Observed changes happened along with the rise of summer $\left(t_{\mathrm{s}}\right)$ and annual $\left(t_{\mathrm{a}}\right)$ temperatures. During 1971-2013 $t_{\mathrm{s}}$ increased by $0.3^{\circ} \mathrm{C}$ per decade $\left(r^{2}=0.32, p<0.01\right)$. Mean $t_{\mathrm{s}}$ in $2000-2013$ was higher on $1.0^{\circ} \mathrm{C}(U$-test, $p<0.02)$ than $t_{\mathrm{s}}$ in the previous 1971-1990. During 1935-2013 $t_{\mathrm{a}}$ increased by $0.3^{\circ} \mathrm{C}$ per decade $\left(r^{2}=0.38, p<0.01\right)$. There were no significant trends of precipitation. 


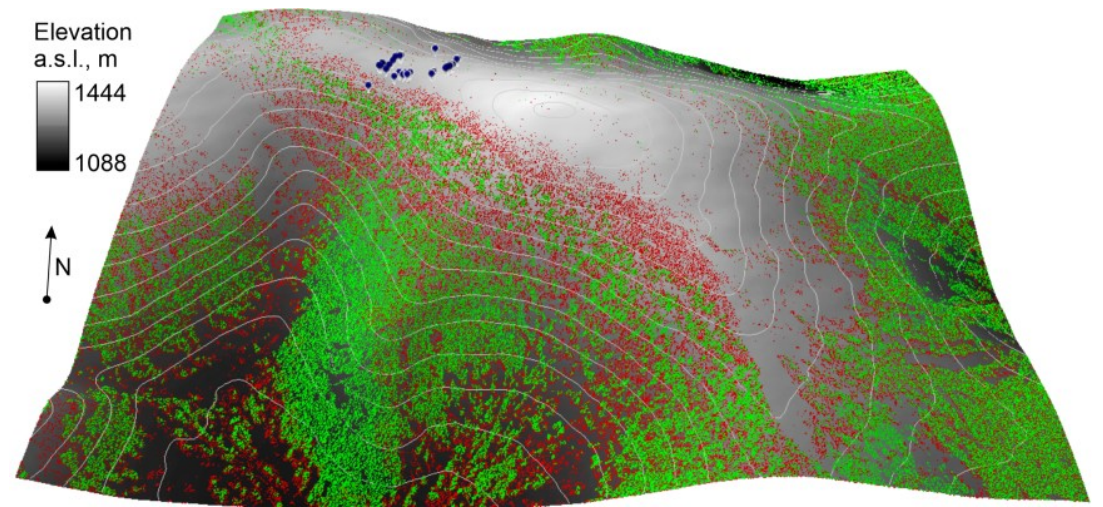

Fig. 2. The classification map of darkneedle stands identified based on the 1971-year CORONA scene (green) and the 2013-year Worldview scene (red). Blue circles indicate ground test sites. Background - SRTM GL1 digital elevation model.

A spatial statistical analysis of the average nearest neighbor analysis (centroids of which located at distance less than $190 \mathrm{~m}$ from each other) and multi-distance spatial cluster analysis (Ripley's K) [6] revealed that trees' clusters form groups - stripes of trees (hedges) (fig. 3a). During 1971-2013 the number of clusters increased by $56 \%$ (1.3\% per year). Clusters form stripes of trees along the north-eastern direction $\left(\sim 36^{\circ}\right)$ which conforms to the winter winds. It is seen on the elevation boundary of the forest-tundra ecotone and proved by on-ground data (fig. 3b). Such groups of trees have resulted from the synergy impact of winds, snow, and water [1].
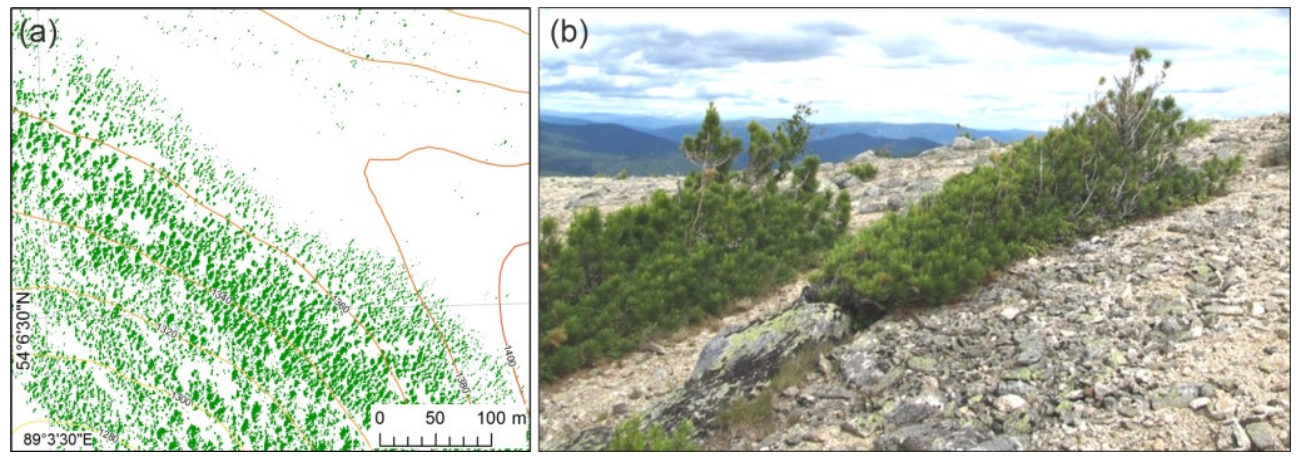

Fig. 3. (a) An example of spatial groups of the identified clusters of trees (green) and (b) the onground photo of Pinus sibirica hedges in the study area.

\section{Conclusion}

In this research spatio-temporal variation of forest-tundra ecotone in Kuznetsk Alatau was investigated based on the CORONA and Worldview remote sensing data. CORONA satellite data in synergy with other spatial materials allow an analysis of dynamics of the forest-tundra ecotone with sufficient accuracy. During 1971-2013 trees' area increased by $0.9 \%$ per year, and the elevation boundary of trees shifted up by $0.2 \mathrm{~m}$ per year. In the analyzed ecotone trees form clusters caused by the impact of winds and snow. Observed changes follow the rise of summer temperature by $0.03^{\circ} \mathrm{C}$ per year during $1971-2013$. 
The research was funded by RFBR, Krasnoyarsk Territory and Krasnoyarsk Regional Fund of Science, project numbers 20-44-240007 and 20-41-240001. Authors thank A. Golyukov and A. Shushpanov for assistance in on-ground studies.

\section{References}

1. X. Lu, E. Liang, Y. Wang, F. Babst, J.J. Camarero, Glob. Ecol. Biogeogr., 30, 305-315 (2021)

2. V.I. Kharuk, S.T. Im, M.L. Dvinskaya, K.J. Ranson, I.A. Petrov, J. Mt. Sci., 14, $442-$ 452 (2017)

3. Declassified intelligence satellite photographs. Fact sheet 090-96, https://web.archive.org/web/20070705233001/http://erg.usgs.gov/isb/pubs/factsheets/fs 09096.html (1998)

4. J.A. Richards, J. Xiuping. Remote Sensing Digital Image Analysis: An Introduction (2006)

5. I.A. Petrov, A.S. Shushpanov, A.S. Golyukov, V.I. Kharuk, Sib. J. For. Sci., 5, 43-53 (2019)

6. P.M. Dixon, Ripley's K Function, in Wiley StatsRef: Statistics Reference Online (2014) 